\title{
Opinion
}

\section{Surrogacy: A Novelty Concept in North Macedonia}

\author{
Daniela Antonovska, MA [Gender Studies]* \\ Skopje, Skopski, North Macedonia \\ "Corresponding author \\ Daniela Antonovska, MA [Gender Studies] \\ Skopje, Skopski, North Macedonia; E-mail: dantonovska@gmail.com
}

\section{Article information}

Received: January $2 \mathrm{I}^{\text {st }}, 2021$; Revised: February $2^{\text {nd }}$, 202I; Accepted: February $5^{\text {th }}$, 202I; Published: February $8^{\text {th }}$, 2021

\section{Cite this article}

Antonovska D. Surrogacy:A novelty concept in North Macedonia. Women Health Open J. 202I; 7(I): 4-6. doi: I0.17|40/WHOJ-7-I40

\section{ABSTRACT |}

Surrogacy has existed since ancient times. Depending on the way of creating an embryo, two types of surrogacy differ, traditional and gestational. When it comes to monetary compensation, two types of surrogacy exist, altruistic and commercialized. A lot of questions come to light such as: Is the altruistic surrogacy a humane gesture for all contracted parties? What if the mother changes her mind? Do the babies born of surrogacy mothers have rights? In North Macedonia, surrogacy was introduced for the first time in 2014 in the amended Law on Biomedicine and Assisted Fertilization. It was a novelty having in mind that in the Law of 2008 the surrogacy as a practice was outlawed. The amended law applies the term gestational mother and provides a liberal stance, but many provisions are unclear.

\section{Keywords}

Laws; Gestational carrier; Commercialization; Altruism; Child rights; Health consequences.

\section{INTRODUCTION}

$\mathrm{S}_{\mathrm{s}}^{\mathrm{u}}$ urrogacy represents a process during which a woman is engaged to carry and give birth to a baby for couples or sometimes a single adult. Depending on the way of creating an embryo we differentiate between two types of surrogacy-traditional and gestational. When it comes to monetary compensation, two types exist-altruistic and commercialized. Women engaged in surrogacy are not free of risks and complication during pregnancy. Some studies showed that apart from death, among surrogates there are cases of preeclampsia, Graves' disease, depression and other diseases. ${ }^{1}$ Having in mind the emotional bond that is created between the mother and the child, are women able so easily to give up the child they are carrying for nine-months? What if they want to keep the child? What are the children's rights in cases of surrogacy? It is not so simple all potentially emerged issues to be regulated by contract and by national laws.

Countries in the world have different laws regulating surrogacy. Countries such as Canada, Australia, Belgium and Greece prohibit commercial surrogacy, whilst allowing altruistic ones. Countries such as Russia, Ukraine, Georgia, allow both types. On the other hand, a vast majority of European countries such as Sweden, Germany, Spain, and France outlawed all types of surrogacy. ${ }^{2}$

In North Macedonia, any type of surrogacy was illegal until 2014. The law as of 2008 prohibited all types of surrogacy.
In 2014 a new law was adopted regulating gestational surrogacy. Provisions in the law prohibit any payments that could commercialize the service by the gestational mother. Whether the new law means progress, a step towards altruism or leaves room for legal abuse? The process of adoption as by the law of 2014 was to a certain extent open and transparent. However, human rights and children rights activists as well as women's organizations were not completely included in the process. Additionally, the perspective of women's and children's rights hasn't been taken fully into account.

\section{SURROGACY MOTHERHOOD AND TYPES OF SURROGACY}

Surrogacy is defined as 'a process through which one or more intended parents contract for a third party — a surrogate — to provide gestational care for and give birth to a child for them'. The process is regulated through a concluded contract between the two parties. Thus, the very course of the pregnancy is contractual.

Whether or not the child would have genetic similarities and/or genetic relationship with the intended parent/s depends on the type of surrogacy. Traditional surrogacy is, among other called 'partial', 'straight' or 'genetic,' whereas the surrogate mother and commissioning father are the genetic parents of the child through artificial insemination. The second type, gestational surrogacy includes implanting an embryo in the surrogate's uterus, whereas the embryo/s is created by the egg/s of the intended mother fertilized 
by the intended father. In this way, the surrogate mother acts only as a gestational carrier. ${ }^{3}$

As far as compensation is concerned, two types of surrogacy are known; altruistic surrogacy where there is no compensation expected and commercial surrogacy, whereby a payment or gains are received. In addition, in the altruistic type only some direct reasonable expenses for the care of surrogate mother are envisaged. On the other hand, commercial surrogacy envisaged monetary compensation for the reproductive care beyond reasonable expenses.

\section{MOTIVATION OF THE INTENDED PARENTS AND SURROGATES}

The primary motivation of intended parents is the infertility of the female or the male partner, repeated failed in vitro fertilization (IVF), congenital abnormalities, life-threatening pregnancy for intended mothers. ${ }^{4}$ However, social stigma around infertility in many countries in the world reinforces the wish of couples and single adults to have children. Although, it is more common in developing countries, many countries in Europe are not immune to the patriarchal matrix that regulates and determines stereotypical gender roles. Having children for both, men and women mean 'regaining social acceptance and dignity. ${ }^{5}$ In North Macedonia, women are predominantly perceived only as mothers.

Most of women in developing countries and in countries with a high rate of poverty engage in the process only for economic benefits. On the other hand, some statements from women in Canada who decided to become surrogates illustrate 'the ability to give something to someone that needed what I could do'. ${ }^{6}$ It is obvious that while, at first sight, there is a difference between surrogate mothers worldwide, and one cannot draw a single conclusion and definition.

\section{HEALTH AND EMOTIONAL CONSEQUENCES SURROGATES FACE}

Pregnancy is often not an easy period for all women including the surrogate mothers. Besides the usual risks associated with pregnancy, such as gestational hypertension and preeclampsia, cases of disability and even death are recorded in surrogate mothers around the world. Some of the risks are fecal incontinence (3\%), depression $(12.5 \%)$, preeclampsia (7\%), and Graves' disease $(6 \%)^{\prime} .{ }^{1}$ The risk is particularly high in multiple pregnancies. The surrogate mother and/ or any woman could not stay detached when alienated from the child. Science has proven that during the pregnancy cells migrate not only from mother to the child, but the other way around and creates a strong bond between the two. ${ }^{7}$ World Health Organization (WHO) recommends exclusive breastfeeding of infants during the first six-months. However, children born of surrogacy usually are bottle-fed with breast milk provided either from the surrogate or from a milk bank. It has always been a dilemma about how a surrogate would feel after giving birth and handing over the child to the intended parents. It is not always predictable that she will not face psychological dilemmas and consequences herself.

\section{ENSURING PROTECTION OF THE RIGHTS OF THE CHILDREN BORN OF SURROGACY}

In surrogacy the rights of the children are rarely considered. Some children are rejected by intended parents due to being born with a disability, with a genetic disease, or in certain cases unwanted twins are rejected as well. There are cases when children born by surrogacy are left without any identification documents and face difficulties registering into the country's legal system. ${ }^{8}$ National laws in countries differ, some allow revealing the truth to the children, and some do not allow it. However, the child is not a product, nor a good that can be arranged by contract. The child is a human being and deserves all rights.

\section{LEGAL FRAMEWORK IN NORTH MACEDONIA}

\section{The 2008 Law}

The Law on Biomedicine and Assisted Fertilization of 2008 clearly stated that surrogacy is prohibited as well as a ban was put on requesting and/or offering such a service. The envisaged fines for violating the ban were calculated to be 1500 to 2500 euros.

\section{The 2014 Law}

The amended Law of 2014 uses the term 'gestational carrier' instead of the term 'surrogate'. A woman can be a gestational carrier if she is a citizen of the county, aged 25 and over, up to the age that allows the woman good physical and mental shape for a healthy pregnancy and to have at least one child of her own. On the other hand, the couples that want to initiate a procedure with a gestational carrier must be married and must be citizens of the country. Married heterosexual couples have a right to submit a request for initiating the procedure with the gestational carrier either if the woman has a congenital/acquired absence of the uterus or congenital anomaly of the ovaries or when the husband has infertility that cannot be cured. This is also in the case when at least three unsuccessful pregnancies of the woman are recorded. The couples that are not officially in marriage and that are in other forms of partnership cannot request for a procedure. ${ }^{9}$ This is a discriminating provision because it ignores the rights of heterosexual couples that are living for many years in unregistered unions.

Only heterosexual married couples can submit a request for engagement of a gestational carrier. Same-sex couples or a single adult (woman or man) cannot request for the procedure. This is discriminate against single adult woman and/or man.

The gestational carrier, according to the provisions of this law, has no parental rights. This is in respect to obligations towards the child and to initiate a procedure for determining maternity or exercise of parental rights. However, the gestational carrier has the right to initiate a procedure for termination of pregnancy up to the expiration of the $10^{\text {th }}$ week. On the other hand, the intended parents also have the right to request termination of the pregnancy of the gestational carrier if medical indications are determined. In certain exceptional cases when the child/children are either left by 
the intended parents or in case both parents are dead, and the child has no other living relative then the gestational carrier has a right to be registered as a mother of the child. In case of death of one of the intended parents, guardianship of the child can be appointed to the other parent.

The child/children have a right to know how they were conceived and born after reaching the age of five. But the law is not very clear whether they have the right to know the gestational carrier or only the way they were born. The Ministry of Health is keeping the record of intended parents and gestational carriers. It is also not clear, and it is not stated who will have the right and permission to look at these records.

Both, the intended parents and the gestational carrier have the obligation prior the surrogacy procedure to go through mandatory psychological counseling as well as through legal counseling. This is a good approach because both parties will become familiar with the process itself.

The law is very clear on the prohibition of the establishment of companies for arranged commercial surrogacy. It prohibits public announcement for the request of compensated surrogates or announcement which offers a paid childbirth service for another. Fines for up to 10 -years imprisonment are envisaged for a physical and legal entity that will be engaged in recruitment and inducement of women under the age of 25 .

However, one article envisages the monthly amount of material costs not to exceed the amount of one average salary in the country. The amount of one average salary is high amount and imposes the question of whether the monthly costs of all pregnant women are reaching approximately this amount. The intended parents must not give gifts to the gestational carrier higher than 100 euros calculated for the entire course of the procedure. But, how this can be controlled and by whom.

\section{CONCLUSION}

Whether or not someone wants to have children is a matter of personal choice. If it is not abused, and if the best interests of all included in the process are well-considered then it could be a noble and human gesture. The whole process should be under the control of the state and of the medical professionals. Every single activity that involves enforcement and coercion should be prohibited. Maternal and reproductive health care as well as childcare should be the priority. Children's rights must be protected. Equal access to health care and all social protection schemes should be ensured and attention should be paid to the long-term consequences on health and emotional well-being of surrogates and children.

\section{REFERENCES |}

1. European Women's lobby. Surrogacy: A global trade in women's bodies. Website. https://www.womenlobby.org/Surrogacy-a-global-trade-in-women-s-bodies. Updated October 31, 2014. Accessed January 21,2021.

2. Cornell Law School. Cornell Law Faculty Publications: Should CompensatedSurrogacy Be Permitted or Prohibited? 2017. Website. http://scholarship.law.cornell.edu/facpub/1551. Accessed January 21, 2021.

3. Cornell Law School. Cornell Law Faculty Publications. Should Compensated Surrogacy Be Permitted or Prohibited? 2017. Website. http://scholarship.law.cornell.edu/facpub/1551. Accessed January 21, 2021.

4. Saravanan S. A Transnational Feminist View of Surrogacy Biomarkets in India. Gateway East, Singapore: Springer Nature Singapore; 2018: 61.

5. Saravanan S. A Transnational Feminist View of Surrogacy Biomarkets in India. Gateway East, Singapore: Springer Nature Singapore; 2018: 63.

6. Surrogacy in Canada Online. Information, referral and Support since 2001, Karen's Story. Website. https://surrogacy.ca/surrogate-mothers/surrogate-mother-stories/karens-story.html. Accessed January 21, 2021

7. Saravanan S. A Transnational Feminist View of Surrogacy Biomarkets in India. Gateway East, Singapore: Springer Nature Singapore; 2018: 19.

8. Crawshaw M, Fronek P, Blyth E, Elvin A. What are children's best interests in international surrogacy? A Social work perspective from the UK. In: Davis M, eds. Babies for Sale? Transnational Surrogacy, Human rights and The Politics of reproduction, Zed Books. London, UK: The Foundry; 2017: 169.

9. Ministry of Health. Law on Biomedicine and Assisted Fertilization. Website. http://zdravstvo.gov.mk/zakon-za-biomedicinsko-potpomognato-oploduvanje/. Accessed January 21, 2021. 